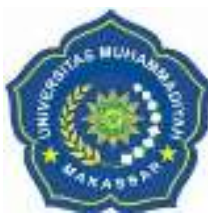

www.unismuh.ac.id
Jurnal Equilibrium Pendidikan Sosiologi

Vol V Mei No. 12017

\title{
Makna Sosial Tongkonan dalam Kehidupan Masyarakat Tana Toraja
}

\author{
Nursalam \\ Program Studi Pendidikan Sosiologi FKIP Universitas Muhammadiyah Makassar \\ nursalam.h@unismuh.ac.id
}

\begin{abstract}
Every society has a norm as a life guide like tongkonan meaning. The purpose of the study is to reveal the history of the formation and the impact of tongkonan as a social phenomenon. The type of research conducted is qualitative research. Informants are determined on the basis of the characteristics of informants that are defined as community members, community leaders, customary leaders. Data collection techniques are observation, documentation and interview. Data analysis techniques through various stages of data reduction, data presentation and conclusion, while the technique of data validity using triangulation of sources, time and techniques. The results showed the history of the process of formation of ongkonan lasted for a long time influenced by the factors of closeness and similarity. Some individuals or communities have a tongkonan due to social customary control factors. Positive implications of Tongkonan meaning are those that have rules, social solidarity, places of need, mutual cooperation, whereas the negative implication is tend to neglect education.
\end{abstract}

Keywords: Social Meaning, Tongkonan, Toraja.

Abstrak. Setiap masyarakat memiliki norma sebagai pedoman hidup seperti makna tongkonan. Tujuan Penelitian untuk mengungkapkan sejarah terbentuknya dan adanya dampak tongkonan sebagai suatu fenomena sosial. Jenis penelitian yang dilakukan adalah penelitian kualitatif. Informan ditentukan secara berdasarkan karakteristik informan yang ditetapkan yaitu anggota masyarakat, tokoh masyarakat, tokoh adat. Teknik pengumpulan data yaitu observasi, dokumentasi dan wawancara. Teknik analisis data melalui berbagai tahapan yaitu reduksi data, penyajian data dan penarikan kesimpulan, sedangkan teknik keabsahan data menggunakan triangulasi sumber, waktu dan teknik. Hasil penelitian menunjukkan sejarah proses terbentuknya ongkonan berlangsung dalam waktu yang cukup lama dipengaruhi oleh faktor kedekatan dan kesamaan. Beberapa individu atau masyarkat yang memiliki tongkonan karena faktor adat kontrol sosial. Implikasi positif makna tongkonan adalah yang memiliki aturan, solidaritas sosial, tempat berbagai kebutuhan, gotong royong, Sedangkan implikasi negatif adalah cenderung mengabaikan pendidikan.

Kata Kunci: Makna Sosial, Tongkonan, Toraja. 


\section{PENDAHULUAN}

Tongkonan merupakan Rumah Adat yang berada di Tana Toraja, tepatnya di wilayah daerah pegunungan bagian utara yang memiliki suhu cuaca dingin dimana Tongkonan tersebut yang berkuasa dahulu terletak di atas puncak-puncak gunung atau bukit dan sampai saat ini semakin bertambahnya Tongkonan di berbagai daerah dan memiliki karakteristik yang berbeda-beda kenapa sehingga dikatakan seperti itu karena setiap Tongkonan yang berjejeran di berbagai tempat atau lokasi bagian daerah. Mempunyai ciri dan perbedaan tergantung Tongkonan tersebut, karena setiap deretan yang ada pada Tongkonan tesebut memiliki perbedaan makna, Adapun yang diketahui tentang Tongkonan memiliki beberapa perbedaan pada perabotan isi Tongkonan diantaranya Atapnya yang melengkung menyerupai perahu kenapa bisa berbentuk perahu karena pada saat penguasa dahulu masyarakat menggunakan perahu untuk menyebrangi sungai yang bernama sungai Sa'dan lalu perahu berhenti di tengah sungai kemudian perahu itu dibawa ke puncak gunung dan perahu itu di bongkar ulang kembali namun dibuat tetap seperti perahu, alasannya karena para penguasa dan bangsawan saat itu akan datang ke puncak gunung yang akan di tempatinya hingga akhinya perahu yang di bedah dan dinamakan Tongkonan.

Tongkonan terdiri atas susunan bambu dan masyarakat Toraja meganggap rumah Tongkonan sebagai ibu sedangkan alang sura (lumbung padi) sebagai Bapak. sampai saat ini pun masih sebagian yang atapnya berupa seng dan bagian depan terdapat deretan tanduk kerbau. Dan sampai saat ini penduduk asli yang ada di Tana Toraja masih sebagian persen yang belum mengetahui tentang rumah adat atau biasa disebut dengan Tongkonan maka dari itu disini saya akan menjelaskan Tongkonan tersebut. Adapun diketahui masyarakat asli Toraja ini Tongkonan biasa di gunakan berbagai acara tertentu yaitu pesta pernikahan, pesta kematian, tempat membuat peraturan dan pembinaan agama atau keyakinan yang disebarkan ke masyarakat, dan adat istiadat dari beberapa yang disebutkan di atas.
Adapun yang paling terkenal dalam berbagai acara adalah yang sering dilaksanakan di Tana Toraja diantaranya, Acara kematian dimana pada saat orang Toraja meninggal penduduknya akan melakukan acara kematian dimana hewan peliharaan atau hewan yang dibeli yaitu kerbau yang biasa di sebut Tedong Bonga dan Babi itu akan dijadikan sebagai taruhan dan akan dilaksanakan perkelahian, pada saat itu pula hewan yang ditaruhkan kemudian Hewan yang kalah akan di sajikan pada orang yang melakukan acara kematian tersebut.

Bangunan Tongkonan dijadikan pusat bujur utara-selatan dan lintang timur-barat. Tongkonan selalu dibangun menghadap $k$ utara dngan pintu utama serta bagian dapur yang selalu mengarah ke timuur ( tempat naiknya matahari). Utara adaah tempat Puang Matua (sang pencipta) bersemayam di tengah langit, sedang timur adalah tempat para dewa pemelihara yang memberi rezeki, kesehatan, dan hal lain.

Fungsi Tongkonan itu pada acara kematian akan digunakan sebagai pengangkat mayat dan orang yang mengangkatnya menari dan di nyanyikan lagu khusus. Adapaun Tongkonan di bedakan atas tiga jenis yaitu. Tongkonan layuk yang mempunyai kedudukan dan peranan sebagai satuan keluarga besar, Tongkonan peka amberan hamper sama dengan Tongkonan layuk yang membedakan wilayah, pengaruh, kekuasaan, dan pembinaan, Tongkonan batu aqiri dimiliki oleh setiap orang Toraja sebagai satu keluarga besar. Dalam kehidupan Toraja memiliki makna dan peranan yang sangat sentral. Oleh karena itu umumnya struktur Bangunan Tongkonan terdiri atas tiga lapisan yaitu atas, tengah, dan bawah pelapisan ini menggambarkan pandangan orang Toraja tentang dunia atas, dunia tengah, dunia bawah. Adapun pembagian tata ruang bangunannya juga memiliki arti tersendiri, melambangkan awal kehidupan dengan bagian belakang rumah menghadap arah selatan yang melambangkan akhir kehidupan rumah berdasarkan tingkatan atau peran dalam masyarakat, banyak rumah adat yang konon dikatakan Tongkonan di sillanan tetapi menurut 
masyarakat setempat, bahwa yang dikatakan Tongkonan hanya 12 diantaranya adalah Tongkonan karua (delapan rumah tongkonan) dan Tongkonan $A^{\prime} p a^{\prime}$ (empat rumah Tongkonan dalam memegang peranan dalam masyarakat sekitar. Rumah tongkonan adalah salah satu arsitektur yang ada di Indonesia yang memiliki ciri dan karateristik yang khas dan berbeda. Bangunan yang dijadikan tempat tinggal selama jangka aktu tertentu. Rumah Tongkonan adalah rumah asli suku toraja. Suku toraja adalah suku yang menetap di pegunungan bagian utara.

\section{METODE PENELITIAN}

Jenis penelitian ini adalah kualitatif dengan metode analisis deskriptif, dan mengunakan rancangan studi kasus. Penelitian kuantitatif adalah suatu prosedur penelitian untuk mendeskripsikan peristiwa atau perilaku orang atau suatu keadaan pada tempat tertentu secara rinci dan mendalam dalam bentuk narasi, dengan menekankan pada sifat kealamiahan sumber data sesuai dengan karakteristik penelitian kualitatif itu sendiri. Disebut sebagai metode kualitatif, karena data yang terkumpul dan analisisnya lebih bersifat kualitatif

\section{PEMBAHASAN}

Buntu kalando yang terletak di kecamatan Sangalla' kurang lebih $8 \mathrm{~km}$ dari makale. Di sini terdapat rumah tradisional milik puang Sangalla' (bangsawan local) yang dulunya digunakan sebagai pusat pemerintahan di masa lampau, ada juga sebuah museum kecil yang memamerkan barangbarang kerajaan mili keluarga bangsawan tersebut. sekarang ini orang sudah tidak bisa pisahkan tongkonan dengan batu ariri, batu ariri yaitu simbol rumpun keluarga tidak mengumpulkan aturan. Dan Musyawarah satu kelompok menyetujui adanya tongkonan, dan Tongkonan menghadap ke utara karena nenek moyang dari utara Tongkonan harus menghadap ke utara

Masyarakat yang tinggal di Sangalla' ini tergolong masyarakat yang memiliki sifat yang cukup baik walaupun masih ada yang cuek dan kurang berinteraksi dengan sesamanya, namun masyarakat setempat tidak ingin mempermasaahkan masalah tersebut, yang penting mereka memiliki saling menghargai satu sama lain. Akan tetapi masyarakat yang lain juga ada yang ingin beinterksi dengan seesiapa pun guna agar mereka lebih di kenal baik lagi dan menjalin hubungan kekerabatan. Adapun masyarakat yang tinggal di Sangalla' orang-orang yang memiliki pekerjaan yang berbeda-beda seperti pegawaipegawai TNI, Polri, dan pegawai yang masih honor mereka rata-rata ada yang pendatang dan ada pula orang yang memang asli di sana tapi kebanyakan mereka yang pekerjaanya sebagai buruh tani adalah mereka orang asli di sana dan yang memiliki pekerjaan sebagai pegawai adalah orang pendatang tetapi tidak semuanya, mereka memiliki kepribadian yang berbeda-beda pula namun di sisi lain juga mereka memilki pekerjaan sampingan dengan mencari penghasilan tambahan untuk masa depannya.

Masyarakat setempat dengan adanya kelas/strata juga masyarakat yang katanya ada yang pilih kasih dan hanya bergabung dengan sesama tingkatannya saja namun dari informan yang mengatakan bahwa tidak semua seperti itu ada juga yang masih bergaul dengan sesiapa saja asal dengan tujuan yang baik atau ingin bersosialisasi ,namun masyarakat yang kalangan menengah maupun bawah tidak mempengaruhi adanya yang tidak mengenakkan seperti itu apalagi yang kalangan dari bawah mereka hanya bisa minder tapi tidak semuanya.

Adapun yang mengenai pendidikan di Kecamatan Sangalla adalah kebanyakan memang bersekolah itu demi masa depan anaknya namun ada yang beberapa tidak bersekolah di sebabkan karena faktor ekonomi atau masalah orang itu entah beliau ingin sekolahh atau memang tidak ada niat ingin sekolah, tapi dari beberapa informan yang telah di teliti terutama yang bekerja sebgai petani mereka mengatakan bahwa kebanyakan oang tua di sini berusaha mencari nafkah sebisa mungkin agar kelak anaknya menjadi kebnggaan keluarga dan bangsa.

Sekolah merupakan media sosialisasi yang lebih luas, dalam pendidikan sekolah mempunyai potensi yang cukup besar dalam pembentukan 
sikap dan perilaku seorang anak, serta mempersiapkannya untuk penguasaan perananperanan baru di kemudian hari di kala anak atau orang tidak lagi menggantungkan hidupnya pada orang tua atau keluarganya. Mengenai stratifikasi sosial masyarakat di sini cukup bagus, baik itu dari status sosial, ekonomi. Dan semua itu tidak ada masalah, dan mereka bisa saling menghargai walaupun mereka berbeda tingkatan namun ada juga yang tidak bersosialisasi kepada orang yang di bawahnya hanya karena strata yang mereka miliki tapi cuman hanya beberapa orang yang seperti itu mereka juga berlomba-lomba mendapatkan pendidikan yang tinggi agar mereka senantiasa di segani dan di hormati oleh masyarakat setempat.

\section{KESIMPULAN}

Tana Toraja merupakan salah satu kabupaten yang berada di provinsi Sulawesi Selatan yang memilki banyak kebudayaan daerah serta tempat wisata yang begitu unik dan menarik. Budaya masyarakat Tana Toraja memliki nilai-nilai kehidupan sosial yang telah diwariskan secara turun-temurun dari nenek moyang kepada generasi selanjutnya yang masih terjaga hingga saat ini. Tana Toraja menjadi tempat wisata yang begitu banyak di minati dari berbagai kalangan. Tempat wisata yang ada di Toraja harus tetap di jaga dan dilestarikan. Terkhusus objek wisata baby grave, Museum, dan bangunan Tongkonan yang lainnya objek wisata yang sangat unik yang banyak menyimpan misteri. Memiliki Tongkonan yang ditempati berbagai acara baik itu dri acara kematian, pesta, syukuran, pernikahan dan tempat berkumpulnya rumpun keluarga.

\section{DAFTAR PUSTAKA}

[1] Cangara, Hafied. (2011). Pengantar Ilmu Komunikasi. Jakarta: PT RajaGraindo persada.

[2] Dahrendorf, Ralf. (1973). Class and Class Conflict in Industrial Society. London : Routledge dan kegan Paul.

[3] Djajasudarma, Fatimah. (1990). Teori Semantik, Jakarta : Erlangga

[4] Garna, Judistira K.(1996). IImu-ilmu Sosial DasarKonsep-Posisi. Bandung: Program Pascasarjana Universitas Padjadjaran

[5] Hayakawa,S.I. (1990). Simbol-Simbol, Komunikasi Antar Budaya. Penyunting : Dedy Mulyani dan
Jalaluddin Rakhmat. Bandung : Remaja Rosdakarya.

[6] Horton, Paul B. Dan Hunt, Chester L.(1987). Sosiologi Jilid 1 Edisi ke 6. Jakarta

: Penerbit Erlangga

[7] Horton, Paul B. Dan Chester L. Hunt. (1984). Sosiology, edisi keenam International Student Edition Tokyo : McGrow - Hil

[8] Idi, Abdullah H \& Hd, Safarina, (2011), (2013) Sosiologi pendidikan individu, masyarakat, dan pendidikan Jakarta PT RajaGafindo Persada

[9] Jhonson, Doyle Paul. (1981). Sociological theory: Classical Founders and Contemporary Perspectives. New York : Jhon Wiley dan Sons.

[10] Johnson, Doyle Paul, (1988), sociological theory classical founders and contemporary perspektives, Jakarta : PT Gramedia.

[11] Johnson, D.P. (1986), Teori Sosiology Klasik dan Modern. Jilid 1 dan 2 Jakarta : Gramedia

[12] Kodang, K. (1960). Ukiran Rumah Toraja : Balai Pustaka.

[13] Kaplan, David dan Manness, Robert. Teori Budaya, Yogykartaa; Pustaka Pelajar.

[14] Koenjaraningrat, (1997). Metode-Metode Penelitian Masyarakat. Jakarta: PT. Gramedia

[15] Lauer H, Robert. (2003). Perspektif Tentang Perubahan Sosia. Jakarta : PT. Rineka Cipta.

[16] Mead, George Herbert. (1971) mind, self and society from the stand point of a social behaviorist.

[17] Narwoko, Dwi. J \& Suyanto, Bagong, (2011). Edisi keempat, Sosiologi Teks Pengantar Dan Terapan. Jakarta: Perna Media Group

[18] Ritzer, Gerorge (2012), (2014 )Teori Sosiologi. Jogyakarta : Pustaka Pelajar..

[19] Sambas Ali Muhidin. (2011). Panduan praktis Memahami Penelitian. Bandung:Pustaka Setia Soekanto, Soerjono. 2012. Sosiologi Suatu Pengantar. Jakarta: PT Raja Grafindo Persada

[20] Soetomo. (2012). Pembangunan Masyaraka. Yogyakarta: Pustaka Pelajar

[21] Sugiyono. (2013). Metode Penelitian kuantitatif, kualitatif dan R\&D.Bandung : Alfabeta.

[22] Susanto, S. Astri. (1985). Sosiologi dan perubahan sosial. Jakarta. Bina cipta

[23] Soeprato, Riyadi. (2002). Interaksionisme Simbolik. Malang : Averroes Press

[24] Setiadi, Elly M, dkk, (2007). Ilmu Sosia dan Budaya Dasar. Jakarta : Kencana

[25] Sutopo, Heribertus (2002). Pengantar Penelitin Kualitatif : Dasar-Dasar Teoritis dan Praktis. Pusat Penelitian UNS. Surakarrta

[26] Soekanto, Soejono. (2009), Pengantar Sosiologi. Jakarta : Lembaga Penerbitan Fakultas Ekonomi Universitas Indonesia

[27] Scott, Jhon (2011), Sosiologi: The Key Concepts. Jakarta : Rajawali Pers 
[28] Tjipto, Subandi, (2009), Sosiologi Pendidikan, Solo: Fairuz Media.

[29] Weber, Max.(1920) "Clas, Status, Party. HIm. 186195 dalam From Max Wber: Essays in Sociology, diedit dan diterjemahkan Gerth, H. H. Dan C. Wright Mils. New York : Oxford University Press, 1958

[30] Tim Penyusun FKIP Unismuh Makassar. 2016. Buku Pedoman penulisan Skripsi (khusus FKIP Pend. Sosiology). Unismuh Makassar : Panrita Pres. 